\title{
Adult Age Differences in Autobiographical Reasoning in Narratives
}

\author{
Monisha Pasupathi and Emma Mansour \\ University of Utah
}

\begin{abstract}
Two studies examined age differences in autobiographical reasoning within narratives about personal experiences. In Study $1(n=63)$, people completed brief interviews about turning points and crises in their lives. Older participants were more likely to narrate crises in ways that connected the experience to the speaker's sense of self, that is, to show autobiographical reasoning. This increase was primarily evident in young adulthood and midlife. In Study $2(n=115)$, adults provided written narratives about heterogeneous autobiographical experiences. Age was associated with linear increases in the likelihood of autobiographical reasoning. The results are discussed in terms of narrative approaches to selfdevelopment across the life span.
\end{abstract}

Keywords: autobiographical memory, self, narrative, meaning making, life span development

How do people maintain a sense of unity and coherence in their sense of self? For many self-researchers working with more traditional measures of self-concept, the issue has been one of unity across different, equivalently abstract self-conceptions separated by domain or relationship (Campbell et al., 1996; Donahue, 1994; Harter \& Monsour, 1992; Higgins, 1996; Markus \& Wurf, 1987). In the present article, we address an alternative aspect of unity and coherence-one that resonates with long-standing philosophical concerns with identity (Locke, 1690/1996). Specifically, we explore how people construct a sense of unity across their lives by creating connections between their experiences and self-views. In doing so, we take a narrative approach to self-development.

\section{Self, the Life Story, and Autobiographical Reasoning}

The self is traditionally conceptualized as a knowledge structure involving beliefs and evaluations about one's characteristics, roles, and capabilities, both current and possible (Harter, 1998; Higgins, 1996; Markus \& Nurius, 1987). Such conceptualizations regard the self as distinct from autobiographical memory in general, although they acknowledge relationships between memory and self (see also Conway \& Pleydell-Pearce, 2000; McAdams, 1996). These views tend to focus on how people may integrate varied aspects of themselves, across different domains (e.g., work, family), different

Monisha Pasupathi and Emma Mansour, Department of Psychology, University of Utah.

Study 1 data collection was supported by National Institute on Aging Grant R01AG08816 (Laura Carstensen, principal investigator). Study 2 data collection was supported by a University Research Grant from the University of Utah and a Proposal Initiative Grant from the College of Social and Behavioral Sciences at the University of Utah (Monisha Pasupathi, principal investigator). We thank Laura Carstensen for her support of data collection for Study 1. Cindy Berg, Kate McLean, Michelle Skinner, and Jack Bauer provided helpful comments on drafts of this article.

Correspondence concerning this article should be addressed to Monisha Pasupathi, Department of Psychology, University of Utah, 390 South 1530 East, BEH-S 502, Salt Lake City, UT 84112. E-mail: pasupath@psych.utah.edu relationships (e.g., spouse, child), or across actual and possible selves. The emphasis of such approaches is twofold. First, researchers explore how individuals integrate currently evident discrepancies, for example, by identifying higher order abstractions that can explain differences in the self in different contexts (Harter \& Monsour, 1992). Second, people may set goals that, if attained, will bring their actual self more in line with their desired possible selves (e.g., Markus \& Nurius, 1987).

In contrast, our approach was grounded in life story and narrative approaches to the study of self (Erikson \& Erikson, 1997; Habermas \& Bluck, 2000; McAdams, 1993). Such approaches emphasize that the development of the self consists of the integration of autobiographical experiences into a coherent life story. The life story is defined as a selective set of autobiographical experiences that, together with interpretations of those events, explain how a person came to be who he or she is and projects a sense of purpose and meaning into the future. Within their life stories, people articulate how they have changed and stayed the same across major life events (McAdams, 1996). The life story serves to create unity across time and experiences, thus enabling a sense of personal continuity across time. That kind of continuity has long been viewed as a major issue, both from philosophical views (Locke, 1690/1996) and from the views of modern cognitive scientists (Neisser, 1988). It is, however, distinct from the type of unity emphasized in traditional approaches, although one can draw links between this temporal continuity and relations between actual and possible selves.

From a life story perspective, the process of creating such unity requires that people engage in what Bluck and Habermas (Bluck \& Habermas, 2000; Habermas \& Bluck, 2000) have termed autobiographical reasoning or the ability to link the self to experiences. Much of this work has focused on how people's narratives about their actual and their once-possible lives construct changes. However, McAdams (1993) and others (Pals, 2006a; Pasupathi, Mansour, \& Brubaker, 2006; Pasupathi \& Rich, 2005) noted that autobiographical reasoning also can construct and highlight ways that one stays similar across time. Regardless of whether similarity or change is constructed in remembering, both types of construction achieve a sense of continuity in the self, or, in Locke's 
(1690/1996) terms, a sense of personal identity. In the present studies, we focused on life span developmental change in autobiographical reasoning reflected in the construction of narratives about personal experiences.

People can draw connections between experiences and self in narratives in many ways, and researchers have explored many more specific types of autobiographical reasoning. One prominent approach has been to examine lessons and insights (Blagov \& Singer, 2004; McLean \& Thorne, 2004, 2006; Thorne, McLean, \& Lawrence, 2004). Lessons are defined as something people have learned from an experience that narrowly generalizes to similar future experiences, such as "I learned it's probably not a good idea to spit at people from bridge tops." Insights are broader inferences that link an event to insights about oneself or one's relationships with others.

Others have explored ways that people find benefits and opportunities to grow from difficult personal experiences (Bauer \& Bonanno, 2001; Bauer \& McAdams, 2005; Davis, NolenHoeksema, \& Larson, 1998; King \& Patterson, 2000; King \& Raspin, 2004; King \& Smith, 2004; Pals, 2006a, 2006b). Such approaches may be thought of as looking at more particular types of insights than the overarching concept noted above. These researchers have explored features of narratives such as selftransformation (Pals, 2006a, 2006b), accommodative change (King \& Patterson, 2000), integrative themes (Bauer \& McAdams, 2005), life themes (Bluck \& Glueck, 2004), the linking of ongoing activities to beliefs about the self (Bauer \& Bonanno, 2001), and biographical coherence markers or self-event connections (Habermas \& Paha, 2001; Pasupathi et al., 2006). The latter are defined as statements within a narrative that draw some type of connection between the event narrated and the person's beliefs about him- or herself in terms of traits, characteristics, and preferences. Note that these elements of narrative are not the same as other aspects of narrative coherence such as whether a story is sufficiently elaborated and internally consistent; they refer specifically to coherence between the narrative and an external construct-the self-concept or the life story of the individual.

In the present study, we focused on self-event connections as an important type of autobiographical reasoning for the integration of self across experiences and time. That is, because self-event connections make explicit links between the events of one's life and the development of one's characteristics and capabilities, they are a type of autobiographical reasoning that is fundamental to resolving the problem of unity in one's self across time.

\section{Development of Autobiographical Reasoning Across the Life Span: Childhood to Adolescence}

For a person to engage in autobiographical reasoning when constructing a personal narrative, at least two prerequisites apply. First, the person must be able to tell the story of an event. Second, the individual must have some sense of self, whether one defines that in terms of knowledge structures or in terms of a rudimentary or emerging life story. Taken together, these two requirements suggest that we will not see abundant autobiographical reasoning in personal narratives until adolescence, as is the case.

The ability to construct simple stories about single episodes emerges between 18 months and 3 years, roughly (Fivush \& Schwarzmueller, 1989; Harley \& Reese, 1999; Howe \& Courage,
1993; Nelson, 1991; Reese \& Brown, 2000), although children increase the sophistication and elaboration of their stories across time. Basic knowledge about the self begins to develop very early in life (Rochat, 2001), and by middle childhood, most children have at least some sense of self in knowledge-structure terms (Harter, 1998; Marsh, Parada, \& Ayotte, 2004).

The life story, on the other hand, is believed to emerge only during adolescence and early adulthood (Habermas \& Bluck, 2000). The late emergence of the life story is attributable to its dependence on the development of other capacities during adolescence (Habermas \& Bluck, 2000; Habermas \& Paha, 2001; Thorne, 2000). For example, in work explicitly focusing on selfevent connections, middle and older adolescents but not early adolescents are able to narrate experiences in ways that reflect how the self caused that experience to occur or how the experience may have changed the self (Habermas \& Paha, 2001). It is interesting that both middle and older adolescents articulated how their own characteristics caused experiences to occur, but only older adolescents drew links between the events of their lives and how those events had changed their characteristics.

\section{Development of Autobiographical Reasoning: Adolescence and Beyond}

There are both theoretical and empirical reasons to expect development in autobiographical reasoning beyond adolescence. Theoretical approaches emphasize motivational changes across adulthood that may influence the way people construct narratives about personal experience. For example, Eriksonian and related views of adult development have emphasized the importance of reviewing one's life in late adulthood, in order to come to terms with the life that was lived, rather than the life that might have been (Butler, 1963; Erikson \& Erikson, 1997). Empirically, the process of life review is most adaptive when it includes qualities that integrate autobiographical recollections with the rememberer's identity (Wong \& Watt, 1991).

Carstensen (1993) proposed in her theory of socioemotional selectivity that late life renders endings highly salient and that this results in an increased importance for meaningful emotional experience. Empirically, the importance of meaningful emotional experience is reflected in different preferences for social partners (Carstensen, 1992; Fung, Carstensen, \& Lutz, 1999; Fung, Lai, \& Ngu, 2001; Lang \& Carstensen, 2002) as well as in changes in emotional experience and emotion regulation (Carstensen, Pasupathi, Mayr, \& Nesselroade, 2000; Gross et al., 1997). It is also reflected in changes in the emotional experience of autobiographical remembering (Pasupathi \& Carstensen, 2003). Speculatively, connecting experiences with one's sense of self during remembering could render those experiences more meaningful and positive, though this has not been tested.

Direct tests of adult age differences in autobiographical reasoning are evident from two studies. Bauer and McAdams (2005), in a fairly small sample of adults ranging from 30 to 72 , found that older adults are more likely to narrate important and transitional life experiences with themes of growth and integration. They did not code for self-event connections specifically, but the types of statements that they would have viewed as reflecting growth through integration overlap substantially with our notion of selfevent connections. For example, integration themes were reflected 
in statements that connected experiences with the person's selfviews. A second study done by Bluck and Glueck (2004) compared adolescent (aged 15-20), younger adult (aged 30-40), and older adult (aged 60 and over) narratives about times when participants felt they had demonstrated wisdom. Younger and older adults, in comparison with adolescents, were especially likely to narrate experiences of wisdom in ways that connected the experience to their own larger life themes or philosophies, again, one type of autobiographical reasoning. The two adult groups did not differ significantly from one another. Thus, one of these studies suggests continued adult age change in the likelihood of displaying autobiographical reasoning, whereas the other suggests change across early to middle adulthood, followed by stability.

Two other sets of empirical findings indirectly suggest adult age differences in autobiographical reasoning. First, some findings suggest that older adults show selected improvements in storytelling ability (James, Burke, Austin, \& Hulme, 1998; Kemper, Kynette, Rash, O’Brien, \& Sprott, 1989; Kemper, Rash, Kynette, \& Norman, 1990; Mergler \& Goldstein, 1983; Pratt \& Robins, 1991), by using a more subjective, interpretive way of storytelling (Adams, 1991; Gould \& Dixon, 1993; Pratt \& Robins, 1991). Autobiographical reasoning is one subset of interpretive story content. The reasons for changes in storytelling ability are not clear and may involve motivation (e.g., Adams, Smith, Pasupathi, \& Vittolo, 2002), increased skill (Mergler \& Goldstein, 1983), or actually be linked to decline in surprising ways (James et al., 1998).

In addition to storytelling changes, researchers working within traditional approaches to self-development have shown curvilinear changes in the complexity of self-conceptions across adulthood, with middle-aged adults showing the most complex, individuated, and integrated self-conceptions (Diehl, Hastings, \& Stanton, 2001; Labouvie-Vief, Chiodo, Goguen, Diehl, \& Orwoll, 1995). Development of the self in this work is viewed as resulting from age-related increases in the ability to integrate emotional and cognitive aspects of experience but also from age-related declines in fluid intellectual abilities in later adulthood. The same two factors might result in similar patterns of age differences in autobiographical reasoning across adulthood.

\section{Summary and Overview of the Present Studies}

The major goal of the present studies was to document a developmental phenomenon for which prior findings had been somewhat equivocal. We hoped to document this phenomenon with a broader and more continuous age sample than in previous studies and across different types of events and modalities of narration than had previously been explored. On the basis of the findings reviewed above, we hypothesized age differences across adulthood in the extent to which people's autobiographical narratives exhibited autobiographical reasoning. We focused on the presence of explicit self-event connections in participants' narratives as indicators of autobiographical reasoning. We examined both linear and curvilinear patterns of age differences, as Bluck and Glueck (2004) found curvilinear change and Bauer and McAdams (2005) found linear change. In the first study, we focused on major life events, narrated in an interview context. In the second study, we focused on a wide-ranging sample of heterogeneous memories elicited by written narratives. Both studies sup- port the existence of age differences in autobiographical reasoning across adulthood.

\section{Study 1: Turning Points and Crises}

Study 1 examined memories of significant events and periods in life, elicited in an interview context. Many narrative researchers believe it is more important to integrate these types of events with the self than more mundane and everyday events (McAdams, Hoffman, Mansfield, \& Day, 1996; Pals, 1999; Singer \& Salovey, 1993). We chose two types of significant events that we believed to differ in the ease with which they could be integrated with the self: turning points and crises. Turning points are by definition part of the life story - that is, they form part of people's autobiographical understanding of how they have become the person they currently are. Crises are events that rattle people's views of themselves and the world, thus presenting greater challenges for linking those experiences to their beliefs about themselves. We wanted to explore whether older adults were more likely to integrate experiences with the self across different types of experiences or whether age differences were more localized within one of these types of events.

\section{Method}

\section{Participants}

Participants in this study were drawn from a larger study of emotion and aging (Carstensen et al., 2000). The larger study included 184 participants recruited by a survey research company, with equal numbers of men and women ranging across the entire adult life span. Sampling was restricted to African Americans and European Americans and was designed to overrepresent African Americans at about one third of the total sample. In addition, sampling was restricted so that the entire age range would be equally represented. Participants were telephoned by the survey company, and if they agreed to participate, were scheduled for an initial session either at the survey company's offices or at Stanford University.

From this larger sample, we randomly assigned 63 participants to complete a brief interview about turning points and crises in the initial session of the study. The remaining participants completed other tasks during that time. The subsample used in the present study ranged in age from 18 to 86 $(M=55.4, S D=23.1)$; approximately $52 \%$ of the sample was under age 65 , and the remainder were older than 65. Approximately half $(n=30)$ were male, two thirds $(n=42)$ were European American, and the remaining 20 participants were African American. According to the survey company's classification, $53 \%$ were white collar, and the remainder were blue collar. Blue collar participants reported an average of 14.5 years of education $(S D=2.7)$. Those participants who completed the turning points and crises interview did not differ significantly from the overall sample in age, gender, or ethnicity. One participant was missing a turning points interview because of an audiotaping failure.

\section{Procedure}

The larger study focused on experience sampling and involved a 2-hr initial session in which participants learned how to operate the pagers that were part of the larger project and completed measures of personality, basic 
Table 1

Examples of No-Connection, Stable, and Change Narratives From Study 2

\begin{tabular}{|c|c|}
\hline Category & Example narrative \\
\hline No connection & $\begin{array}{l}\text { In July 1997, I took a raft trip on the middle fork of the Salmon River in Idaho. This was a self-guided trip } \\
\text { without "guides." The trip preparation was uneventful, but from the time we left Boise, it was anything but on } \\
\text { the way to the launch site one of the vehicles. }\end{array}$ \\
\hline $\begin{array}{l}\text { Stable self explains-is illustrated } \\
\text { by event }\end{array}$ & $\begin{array}{l}\text { Late last year, a close friend hosted a Christmas party at a rental in Park City. She knew that I was a pretty } \\
\text { good cook and invited me to cater it. My friend (we'll call her Lois) is around my mother's age, so I didn't } \\
\text { really expect to be invited at all. Therefore, I was flattered when she included me, if only as the help. Lois } \\
\text { provided some of the recipes and asked me to come up with some of my own. She gave me the credit card } \\
\text { and sent me to the market for the ingredients. Eight hours later, the guests began arriving just as I dished up } \\
\text { the last menu item. Things went even better than expected. }\end{array}$ \\
\hline Event changes self & $\begin{array}{l}\text { I've always wanted to write my autobiography but never found the time, and when I did, I discovered I was not } \\
\text { sure I wanted to expose my families secrets, sadness, failing, and unhappiness. I finally decided to go ahead } \\
\text { but not tell anyone in my family. At first I wrote in a superficial manner-that was } 5 \text { years ago-now, I'm } \\
\text { able to go more in depth, and as I write, I've found more compassion for those people who shaped my life." }\end{array}$ \\
\hline
\end{tabular}

Note. Underlining indicates the relevant text that led to the coding decision.

demographics, cognitive functioning, and social support networks. ${ }^{1}$ In that initial session, participants randomly drawn for the present study completed a brief interview. The interview took place after the participants had spent substantial time with the experimenter and consisted of two segments: a turning points segment and a crisis segment. The order of the segments was counterbalanced and did not influence the results reported below. Interviewers were all college-aged women who went through a standardized training procedure that included videotaped interviews and feedback. The prompts used were nonverbal encouragers such as "mmmmm" and "uh-huh" and (for cases in which participants paused) "Is there anything more you can tell me?" We did not standardize prompts beyond providing these prompts on the interviewer's script. Neither the particular interviewer nor the number of prompts given were related to the findings reported here.

For turning points, participants were asked first to think about and list turning points in their lives. Participants were then asked to select one turning point and talk about it in more detail: "Can you tell me everything about this particular turning point?" For crises, participants were asked if they had ever experienced something like a crisis "or a time when you doubted yourself" and again were asked to select one such crisis to discuss in more detail. Aside from the initial request to talk about a selected turning point-crisis, interviewers were instructed to provide nonspecific prompts and back channels, until the participant indicated there was nothing more to say. At the end of each segment, participants were asked to talk more explicitly about their emotions at the time. Each participant generated two interview narratives, one regarding a turning point and one regarding a crisis. A wide range of experiences was nominated, from deaths, divorces, and abuse experiences to dilemmas about applying to medical school and the rewards of pursuing one's own business.

Following the interview and the end of the first session, participants provided 1 week of experience-sampling data and returned for a debriefing session. Participants were compensated $\$ 100$ for participation in the entire protocol. The present study focused only on the interview data and demographics data gathered in Session 1.

\section{Measures}

Narrative coding for autobiographical reasoning. Autobiographical reasoning is broadly defined as the construction of connections that link experiences to the person's sense of self. Our initial coding scheme (Pasupathi et al., 2006) involved five possible types of connections: (a) the event is explained by or illustrates a preexisting quality of the self, (b) the event appears to indicate some new quality but should be dismissed or ignored, (c) the event caused a change in my self-views, (d) the event revealed a preexisting but previously unrecognized quality of myself, and (e) no connection to self. Each narrative was coded as belonging to one and only one category, and coders relied on the presence of very explicit statements by the participant. This coding scheme is primarily independent of other aspects of narrative such as coherence and elaboration. Note that a narrative could vary considerably in terms of narrative coherence but still contain self-event connections. Moreover, narratives could be impoverished in detail but still contain self-event connections and vice versa. This is important, because we were focused here on the issue of integration of self and experience, as assessed within narratives, but we were not focused on capturing the relative coherence or elaboration of the narratives themselves.

Because some of our categories (dismiss and reveal) were extremely infrequent in the interviews, we collapsed these five codes into three: no connection to the self, a stability relation (which included the explainillustrate category and the extremely infrequent dismiss category), and a change relation (which included both cause and reveal relations). Our rationale for this was fairly straightforward: Dismissals explicitly take up the issue of a self-event connection and deny that one exists, thus maintaining a stable sense of self. Reveal connections also explicitly note change in the self-view but view that change as being due to the event causing a shift in perspective on the self. Emma Mansour served as the primary coder and provided the codes used in analyses reported below; Monisha Pasupathi served as the reliability coder for Study 1. During coding, Emma Mansour was blind to the primary hypotheses of the study and had no access to data on participants' ages or other characteristics. Reliabilities for 30 stories (25\% of the total sample) across the three collapsed codes was good, with coders agreeing $83 \%$ of the time $(\kappa=.74)$, $t(29)=5.6, p<.01$. Examples of the three categories are provided in Table 1; the relevant text that led to the coding decision is underlined.

Validity. This is a novel way to assess autobiographical reasoning and may be understood as an expansion of initial work by Habermas and Paha (2001). In their approach, they collected life story narratives from a small sample of adolescents and identified the number of self-event connections in which the self caused an experience and in which the experience changed the self. Their work suggests that these types of connections are quite rare and increase with age during adolescence, providing some

${ }^{1}$ Age was significantly associated with cognitive performance, as indicated by the Wais digit-symbol test and a verbal fluency task (see Carstensen et al., 2000), but inclusion of these variables did not change any of the results reported above. 
preliminary validity of the developmental changes expected in this measure. A further validity issue is the extent to which our coding scheme captured the way participants themselves think about the experience when prompted. Elsewhere, we have collected validity data on the coding scheme by comparing our coding of written narratives and participants probed responses elicited after they produced their written narrative ( $\mathrm{Pa}-$ supathi \& Mansour, 2003). Autobiographical reasoning indicators coded from participants' unprompted narratives are typically consistent with what participants say when asked explicitly to create such connections. Across 96 responses, participants' responses to direct autobiographical reasoning probes seldom conflicted with our coding of their initial narrative (for stability connections, only 6 of 96 participants, and for change connections, only 9 of 96 participants reported probed responses that conflicted with their narratives).

For our analyses, both change and stability connections reflected the presence of explicit autobiographical reasoning. So, for our primary analyses, we collapsed across stability and change connections and contrasted narratives involving either type of connection, with narratives involving no connection.

\section{Results and Discussion}

We first examined whether gender or ethnicity was related to the likelihood of self-event connections either independently or in interaction with age. They were not, and these factors are not considered further. Overall, $62 \%$ of turning points and $70 \%$ of crises were narrated with no self-event connections, and this is typical of work with narratives (McLean \& Thorne, 2004; Thorne et al., 2004). Looking only at those participants who did express self-event connections, such connections were descriptively more prevalent for turning points $(n=32)$ than for crises $(n=20)$. Across both types of events, self-event connections in which the event changed the self were more prevalent than those that invoked stability: For turning points, $22 \%$ ( $n=7$ of 32 ) used stabilitypromoting connections, and for crises, $40 \%$ did so ( $n=8$ of 20 ).

To explore whether age was significantly associated with whether participants included any self-event connections in their narratives, we computed two logistic regressions, one for turning points and one for crises. In each case, we included both linear and quadratic effects of age in the model. For turning points, age had no impact on the likelihood of self-event connections, with the overall model, $\chi^{2}(2, N=62)=1.7, p>.40$, and the linear and quadratic age factors failing to attain statistical significance.

For crises, in contrast, age was significantly related to selfevent connections, $\chi^{2}(2, N=63)=6.2, p<.05$, and the nature of this relationship was nonlinear. The linear effect of age was positive, suggesting that with increasing participant age, selfevent connections were more likely $(B=.21)$, Wald's $\chi^{2}(1, N=$ $63)=4.7, p=.03$. The quadratic effect of age was negative $(B=$ -.002), Wald's $\chi^{2}(1, N=63)=4.4, p<.04$. In order to better illustrate the data, we show in Figure 1 the percentage of people in each age group whose crisis narrative contained a self-event connection. Examination of Figure 1 suggests that one way to interpret these findings is that age is related to increases in the likelihood of self-event connections in narratives through middle age, but this increase then levels off, such that the primary arena for change occurs between young adulthood and middle age (the peak of the curve occurs between the ages of 50 and 70 years). In order to descriptively illustrate the findings, we computed correlations between age and self-event connections separately for participants under $60(n=32)$ and over $60(n=31)$ years of age.

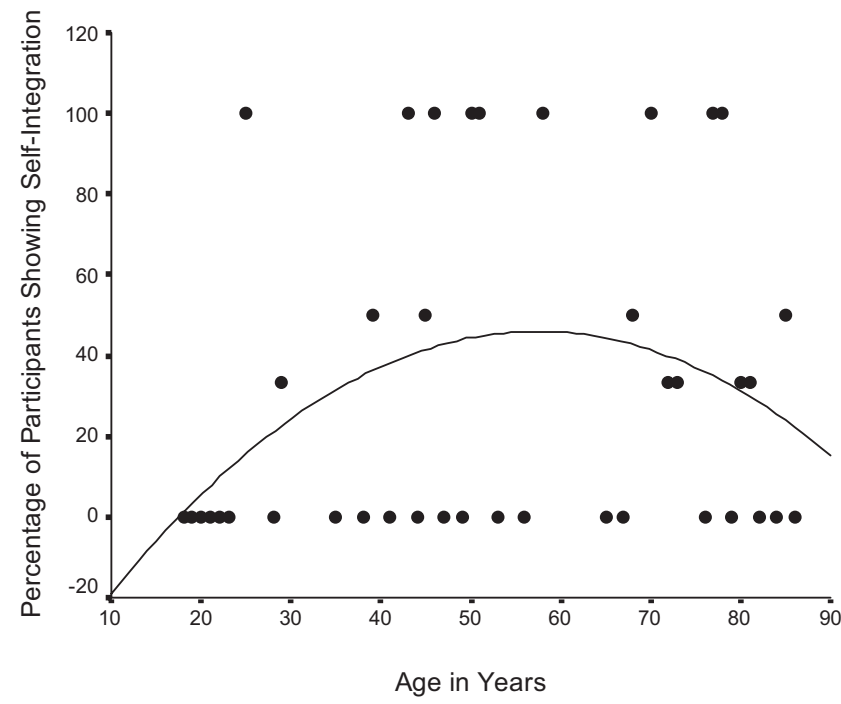

Figure 1. The percentage of participants at each age (represented by dots) whose crisis narratives reflected self-event connections in Study 1. The line represents the quadratic relationship between age and self-event connections.

For those under 60 , this correlation was significant and positive $(r=.38, p<.05)$. For those over 60 , this correlation was negative but smaller in magnitude and not statistically significant $(r=-.12$, $p>.50)$. The same pattern is evident when other cutpoints, such as 50 or 70 , are used. The correlational results cannot be taken as equivalent to post hoc tests but do suggest that the quadratic pattern observed may be asymptotic rather than an inverted $U$.

These results suggest that there are changes across adulthood in the likelihood of explicit autobiographical reasoning, differences that are primarily evident in crises, rather than in turning points. They further suggest that this pattern is curvilinear in nature, with increases in the likelihood of such reasoning from young adulthood into middle adulthood, followed either by a leveling off of those increases or by the beginnings of declines. Finally, this pattern was consistent across men and women and across two different ethnic groups.

\section{Study 2: Heterogeneous Events and Written Narratives}

The major purpose of Study 2 was to replicate and extend findings from Study 1 with a more heterogeneous set of events and a different remembering modality-writing. These changes address two limitations of the data used in Study 1. First, more heterogeneous events allowed for greater variability in the selfimplications of the recalled experiences than was the case in Study 1 , which limited the selection of events to those that clearly had self-relevant implications. The extension to a written mode of recall addresses the possibility that interviewers in Study 1, all of whom were young adult college students, responded differently to older adults than to younger adults, thus eliciting different content, or that older adults responded differently to the intergenerational task of talking to our younger adult interviewers than did younger adult participants.

In Study 2, we also obtained additional information about the events narrated, including their importance and emotionality. This 
information is important in exploring whether adults of different ages were actually recalling events that contained more or less potential for self-event connections. That is, it is possible that the age-related differences we observed in Study 1 were due to the types of events people select to recall? Finally, we were also able to examine alternative indicators of "age," including the age of the event and the participant's age at encoding versus age at retrieval (i.e., during participation). Events that have been retained for a longer period of time are more likely to be self-defining and thus to be narrated with explicit autobiographical reasoning. Earlier work has shown that age at encoding also influences the way people construct narratives of autobiographical experiences (Conway \& Holmes, 2004; Thorne, 1995).

\section{Method}

\section{Participants}

Participants were 115 volunteers (42 men and 70 women; 3 additional participants did not report their gender) recruited from the Salt Lake Valley, Utah, metropolitan area to participate in a study of memory telling (Pasupathi, 2003). ${ }^{2}$ Recruitment was done through flyers and newspaper advertisements, and participants were compensated $\$ 10-\$ 15$ for participation, depending on how long it took them to complete the questionnaires (between 1 and $1.5 \mathrm{hr}$ for most participants). The participants ranged in age from 18 to $89(M=43, S D=19)$, with approximately $87 \%$ of the sample under age 65 and $72 \%$ under age 50. Participants reported an average of 14.4 years of education $(S D=2.9)$. The sample was overwhelmingly European American (81\%), consistent with the general population of Utah, precluding any examination of ethnicity.

\section{Procedure}

Participation took place individually in our laboratory or in small-group settings in residential communities. Participants completed a lengthy questionnaire focused on experiences that they had talked about with other individuals. The questionnaire initially asked participants to think of an experience and to "describe the experience" in writing. Experiences ranged widely, from returning items to a store to a disclosure of childhood sexual abuse. Participants were then asked to report when the event occurred and to rate, using 7-point Likert-type scales, how important the event was, the emotions they felt when the event occurred, and how much it revealed something about who they are. Participants were also asked questions about the disclosure of the event and how listeners responded to the disclosure. These data were not used for the present study and are not discussed further. ${ }^{3}$

\section{Measures}

Narrative coding of autobiographical reasoning. Narrative coding of autobiographical reasoning was done as in Study 1. Initial coding was done with the five-category system and collapsed to three categories examined in Study 1. Coding was done by Emma Mansour, who was blind to age and to the primary hypothesis while scoring protocols. An undergraduate research assistant was trained to apply the coding system based on a manual and a subset of the data. This assistant then independently coded 20 narratives (18\% of the data) to establish reliability. Reliability was good (95\% agreement, $\mathrm{\kappa}=.85), t(19)=5.8, p<.01$.

Event characteristics. Participants rated on a single Likert-type scale the importance of the event $(1=$ not important, $7=$ very important $)$ and the extent to which the event revealed something about who they are $(1=$ not at all, $7=$ very much). Participants also rated the emotions elicited by the event initially across eight positive emotions (happiness, joy, content- ment, excitement, pride, accomplishment, interest, and amusement), using a 7 -point Likert scale $(1=$ not at all, $7=$ the most ever $)$. We averaged across the eight terms to create an index of initial positive emotions elicited by the event $(\alpha=.92)$. Participants reported how long ago the event occurred, and from this report we computed the age of the event in years as well as the age of the individual when the event occurred.

\section{Results}

\section{Preliminary Analyses}

The events narrated by participants were on average fairly important $(M=5.9, S D=1.6)$ and self-revealing $(M=5.6, S D=$ $1.8)$ but not especially emotionally positive $(M=3.4, S D=1.9)$. Participants reported that events had occurred an average of 7 years ago $(S D=15)$, with a range from the same day as the study to 65 years earlier. About $76 \%$ of the narratives were coded as having no self-event connections, and of those coded as having connections $(n=28), 39 \%$ were stability connections and $61 \%$ were change connections.

Were event characteristics associated with the presence of autobiographical reasoning? Because the different event characteristics above were intercorrelated $(0<r s<.41)$, we examined whether the presence or absence of self-event connections was associated with any of those features using a multivariate analysis of variance, with importance, self-revealingness, emotional positivity, and age of the events as dependent variables and the presence-absence of self-event connections as the independent variable. The results revealed an overall main effect of self-event connections, $F(4,103)=2.5, p<.05, \eta^{2}=.09$. Inspection of the univariate $F$ values suggested this main effect was primarily due to relations between the presence of self-event connections and ratings of the extent to which the event was self-revealing, $F(1$, 106) $=9.4, p<.01, \eta^{2}=.08$. Events narrated with self-event connections were rated as more self-revealing $(M=6.4, S D=1.3)$ than were events narrated with no such connections $(M=5.3$, $S D=1.9$ ). This finding lends further support to the validity of our coding scheme.

Was age related to any of the event characteristics? We computed Pearson product-moment correlations between age of participant and the importance, self-revealingness, insightprovoking quality, and age of the events they recalled. Not surprisingly, older adults were providing memories of older events $(r=.37, p<.01)$ but did not view their events as more selfrevealing $(r=-.02)$, emotionally positive $(r=.08)$, or important $(r=.11, p>.20)$. This finding suggests that any age effects on the prevalence of self-event connections could be attributable to the

\footnotetext{
${ }^{2}$ The primary purpose of the original study was not to examine age differences but to explore a variety of aspects of memory telling in everyday life in a heterogeneous, noncollege student sample. Thus, the age distribution in the present study is not ideal.

${ }^{3}$ Pasupathi and Carstensen (2003) reported on emotion ratings as a central variable in a set of studies on emotional experience while participants were engaged in memory telling. As reported in Pasupathi and Carstensen, participants of different ages reported events with similar emotional properties initially, although older adults reported more positive emotion during retelling. The present study is focused on something different - namely, the nature of participants' memories. The memories themselves were not included in the previous work.
} 
age of the event but were not likely to be attributable to age differences in the types of events selected for reporting in this study. As in Study 1, we also examined whether gender had main effects or interacted with age in predicting self-event connections. This was not the case, and gender was excluded from the analyses reported below.

\section{Are Older Adults More Likely to Integrate Events With the Self Than Younger Adults?}

We conducted a logistic regression predicting whether participants' narratives involved self-event connections, based on participant age and the extent to which the event was self-revealing. The regression was conducted in a hierarchical, stepwise fashion, with self-revealingness and age of event entered on a first block, the linear effect of participant age entered on a second block, and the quadratic effect of age entered on a third block. ${ }^{4}$ The second model, including all three predictors, significantly predicted the presence of self-event connections, $\chi^{2}(3, N=109)=18.0, p<$ .01 . The extent to which the event was perceived as self-revealing significantly predicted autobiographical reasoning, Wald's $\chi^{2}(1$, $N=109)=7.3, p<.01(B=.55)$, as did the participant's age, Wald's $\chi^{2}(1, N=109)=7.2, p<.01(B=.04)$. Results from the third model, in which a quadratic effect of age was added, suggested that there was no quadratic effect of age, $\chi^{2}(1, N=109)<$ 1. The age effect is shown in Figure 2, again, in terms of the number of individuals at each age whose narratives displayed self-integration. As presented there, age was associated with an increasing frequency of autobiographical reasoning. This replicates the linear age effect observed in Study 1 with a more heterogeneous set of experiences and when controlling for important potential differences in the types of events people of different ages might be remembering. We did not replicate the quadratic effect of age, and it is likely that this is due to the fact that in this study, we had fewer participants over the age of 65 years. Notably, Bauer and McAdams (2005) had relatively fewer very old partic-

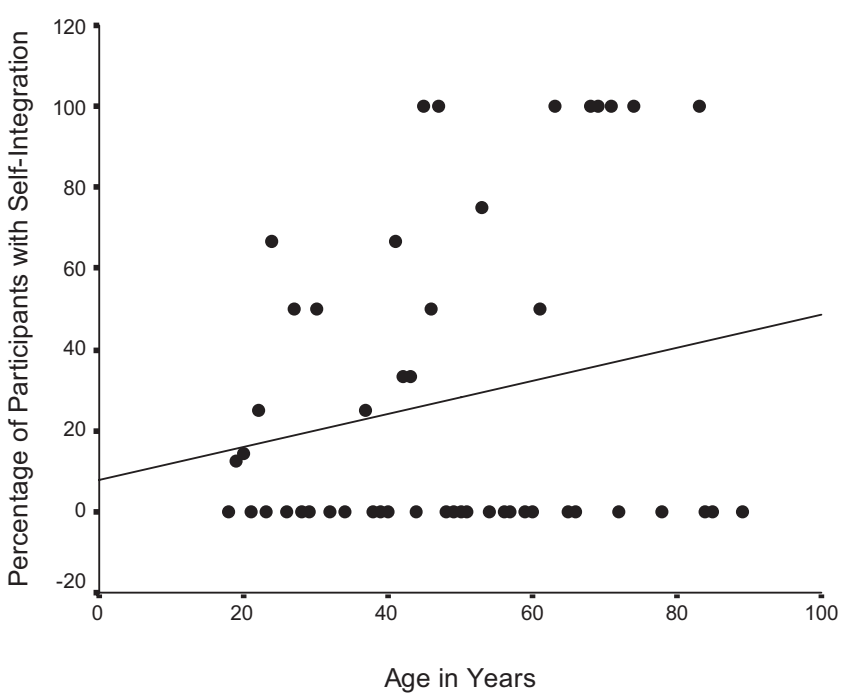

Figure 2. The percentage of participants at each age (represented by dots) whose narratives reflected self-event connections in Study 2. The line represents the linear relationship between age and self-event connections. ipants (none over 72 years of age) and also did not find a quadratic effect of age.

We considered whether the effect of age was due to age at retrieval or age at encoding. Both age of the rememberer $(r=.20$, $p<.04)$ and age of the experiencer $(r=.26, p<.01)$ were significantly and positively correlated with the likelihood of autobiographical reasoning in the narrative. However, in the present data, these two variables were too highly intercorrelated $(r=.69)$ for statistically testing this possibility, and the small differences between these two correlations were sufficiently large to be statistically reliable.

\section{General Discussion}

The results presented above suggest that middle-aged and older adults are more likely than younger adults to demonstrate explicit autobiographical reasoning when constructing autobiographical narratives. This age difference was present in both interviewelicited and written narratives and for both significant and heterogeneous life events. The findings also suggest that age differences are more evident in contexts in which drawing self-event connections is more problematic - that is, when the events being narrated are heterogeneous in their potential for meaning or in the case of crisis events that challenge participants' existing self-conceptions. For turning point events, which are by definition already part of the individual's life story, we did not observe any age differences.

The two studies both suggested linear age-related increases in the likelihood of autobiographical reasoning across young adulthood and into middle age. In this sense, these findings are very consistent with earlier work by Bluck and Glueck (2004) and Bauer and McAdams (2005). Both of those studies showed adult age differences consistent with our findings. In Bluck and Glueck's work, those differences could be described as increases between late adolescence and early middle age, followed by stability. In Bauer and McAdams's findings, linear increases were observed in adults ranging from 30 to 72 years of age. The consistency across these three studies emerges in spite of differences among the studies in terms of samples, narrative elicitations, and the specific types of autobiographical reasoning that were explored.

The details of the pattern of age-related differences in adults over 65 are not as clear. In Study 1 and in Bluck and Glueck (2004), where there were a large number of adults over 60 in the sample, age-related differences diminished or changed direction later in adulthood. In Study 2, as in Bauer and McAdams (2005), with fewer adults over the age of 60 , we found evidence for linear change. Study 2 may have yielded a curvilinear component given a larger sample size in the older adult range. In fact, computing simple correlations in the under-60 and over-60 participants in Study 2 separately yields a small positive correlation $(r=.08)$ for the under-60 individuals and a small negative correlation $(r=$ $-.09)$ for the over-60 individuals. Neither of these correlations is statistically significant, but the pattern is consistent with findings

\footnotetext{
${ }^{4}$ We also tested for whether age interacted with self-revealingness or the age of the event, such that age differences were moderated by these two features of the events narrated. This was not the case, suggesting that age differences were independent of these two features of the events.
} 
from Study 1. Still, future work examining autobiographical reasoning will need to adequately sample across adulthood to better establish the full pattern of age-related differences suggested by current findings.

The present data leave unanswered two important questions for future investigations. A first question concerns the source of age differences - that is, what are the developmental mechanisms that promote autobiographical reasoning? A second set of questions concerns the adaptiveness of such reasoning. Next, we consider some speculations about the origins and implications of autobiographical reasoning as well as how those speculations might be examined empirically in future work.

\section{What Leads to More Autobiographical Reasoning With Age?}

One possibility is that the differences observed are linked to motivational changes, with age identified in socioemotional selectivity theory, such as an increasing emphasis on more meaningful experience and on emotion regulation (Carstensen, 1995; Carstensen et al., 2000) as well as an increasing emphasis on remembering to integrate across one's life, based on developmental tasks approaches (Erikson \& Erikson, 1997). One way to ensure meaningfulness in the context of autobiographical narration is to construct connections between events and one's sense of self. Other work addressing socioemotional selectivity theory has used experimental manipulations of the salience of endings and questionnaire measures of perceptions of future time. Both approaches could conceivably be used to examine how individual differences in future time perspective, or experimentally manipulated differences in ending salience, influence the extent to which people create self-event connections in narratives. An Eriksonian approach would need to develop ways to experimentally manipulate the salience of a task such as life review (Butler, 1963) to use similar approaches.

A second possibility is that developmental changes in more traditional aspects of the self lay a different cognitive foundation for autobiographical narration-one that promotes autobiographical reasoning. As noted earlier, findings suggest that the most complex, individuated, and integrated self-conception is evident in late middle age (Diehl et al., 2001; Labouvie-Vief et al., 1995). This complex and unified self permits greater scope for integrating new experiences with the self when telling personal stories, because a more complex self can be more easily connected to a greater variety of personal experiences. These findings also suggest that any age-related changes in the likelihood of autobiographical reasoning in narrative may be curvilinear in nature, mirroring changes in the structure of self-conceptions. In future work, this possibility could be empirically evaluated with the inclusion of measures of self-concept clarity (Campbell et al., 1996), self-concept complexity (Labouvie-Vief et al., 1995), or self-concept differentiation (Diehl et al., 2001; Donahue, 1994). A related alternative here is that linear increases in the prevalence of self-event connections with age are constrained by changes in basic cognitive functioning in very old age, resulting in the curvilinear patterns observed in self-descriptions and, to some extent, in indicators of autobiographical reasoning.

Age differences in autobiographical reasoning could reflect more general changes in storytelling, as also noted earlier. Older adults make better storytellers from the view of listeners (James et al., 1998; Kemper et al., 1989, 1990; Mergler \& Goldstein, 1983; Pratt \& Robins, 1991) and may emphasize subjective aspects of stories, such as interpretation and elaboration, more than younger adults (Adams, 1991; Gould \& Dixon, 1993; Pratt \& Robins, 1991). Because autobiographical reasoning is one aspect of interpretive and elaborative remembering, its presence may reflect a more general tendency evident in both personal and nonpersonal stories.

Finally, our findings are inconclusive about the role of age at remembering (the basis for our analyses) versus age at encoding. That is, age differences may have emerged in these studies because older experiencers make sense of events differently when those events occur or because older rememberers recall those events differently when reconstructing them from memory. In past research, there is evidence that the age of the individual at the time events occurred can influence how they recall the event at some later time (Conway \& Holmes, 2004; Thorne, 1995). In Study 2, both age at encoding and age at recall predicted increases in self-event connections, but these two measures were so highly intercorrelated that we could not analyze them independently. Future work aiming to distinguish these possibilities might explore contrasts between older and younger adults' recollection of recent versus distant past experiences, in order to disentangle these issues.

\section{Is the Creation of Self-Event Connections Adaptive?}

A second issue, of course, is whether these age differences are linked to larger developmental gains. For the individual, integrating important life events with the self may be consequential for mental and possibly even physical health, as suggested by work on the "writing cure" (Pennebaker \& Keough, 1999; Smyth, 1998) and by research on bereavement (Bauer \& Bonanno, 2001). In the latter work, widows and widowers who integrated accounts of their experiences ("doing") with understandings of themselves ("being") did better over time than those who did not make these connections. In this light, the age differences observed here can be viewed quite positively. Moreover, other researchers studying similar features of narratives, such as accommodative change (King \& Patterson, 2000), self-transformation (Pals, 2006a, 2006b), and integrative themes (Bauer \& McAdams, 2005), have often shown links between the prevalence of those elements in narratives and well-being and maturity more traditionally defined (e.g., Bauer \& McAdams, 2005; Blagov \& Singer, 2004; King \& Patterson, 2000). It is important to note that Pals's (2006a, 2006b) work distinguishes between positive and negative changes in the self as articulated in narratives and highlights the fact that, as examined here, we have not addressed the valence or specific content of self-event connections. Linking a negative event to the self in a stable way could be destructive-undermining the confidence individuals need to grow. However, dismissing negative experiences might also deprive individuals of the possibility for change. Thus, self-event connections as we have examined them here leave room for more specific analyses; more specificity may be necessary to fully examine issues of adaptivity.

In addition, autobiographical reasoning may be an important feature of narrative remembering that helps to create intimacy and connections between people. From this perspective, people who 
engage in this type of remembering in social contexts may also benefit in an interpersonal sense, although this is more speculative (Alea \& Bluck, 2006).

\section{Some Limitations of the Present Findings}

Of course, the present findings have several limitations. As already noted, the age distributions of the two samples varied, and this makes it unclear whether self-event connections decline in frequency in later life or whether increases in such connections simply level off. The replication of the linear effect across samples that differed in their representation of young and middle adulthood is reassuring. Moreover, the data are cross-sectional in nature; thus, a generational differences explanation cannot be ruled out. This is especially important because an emphasis on integrating events into a coherent life story may be a cultural-historical emphasis that is sometimes argued to be diminishing in Western cultures during current times (Gergen, 1991; Lifton, 1999). Thus, it is possible that age differences really reflect ongoing generational shifts in the desire to integrate experiences with the self across the successive generations included in both studies.

It remains a possibility that older adults and younger adults are essentially recalling different types of experiences, with older adults focusing on more self-relevant events than younger adults. This explanation, however, is made less likely on the basis of a number of features of our two studies. First, in Study 1, both older and younger adults were recalling major, personally significant life events. Across both studies, a scan of the content of narratives reveals that by and large, events related by older and younger adults in both studies were connected to the self, regardless of whether participants explicitly drew such a connection in constructing the narrative. For example, in both studies, young adults talked about career choices, relationship events, mistakes, and failures, and older adults spoke of retirement, losses, past successes, good and bad relationships, relational conflict, and so forth. That is, the age differences in narrative construction are difficult to explain by the assertion that younger adults were simply choosing to narrate events unconnected to their sense of self.

Other limitations include the relatively small sample sizes, our broad categories for coding autobiographical reasoning, and the relatively high prevalence of no-connection narratives. The high prevalence of no-connection narratives is consistent with other findings in the narrative field (see also McLean \& Thorne, 2004; Pasupathi et al., 2006; Thorne \& McLean, 2003). However, it raises the issue that perhaps storytelling is not the most important path by which people construct their own development over time. One possibility is that individual differences play an important role in which people emphasize the construction of a narrative self and which individuals do not. For example, extraversion is associated with increased frequency of narrating personal experiences and increased comfort while doing so (McLean \& Pasupathi, in press). Extraverts may, as a consequence, be more story focused in their self-construction than less extraverted individuals. Other individual differences may also play a role, such as ego development (King \& Raspin, 2004) or differences in self-awareness or the tendency to seek insights from one's experiences.

Other explanations for no-connection narratives emphasize the discursive context. In the case of Study 1, that context involved explicit statements about the meaning of the event from the inter- viewer (i.e., "a crisis, or time when you doubted yourself"). Thus, for participants in Study 1, the meaning of the event may be excluded from the narrative because it has been provided by the interviewer and is thus a given; perhaps this was especially true of younger adults? However, Study 2 provided no such context and yielded even higher percentages of no-connection narratives. Further, age differences emerged regardless of the extent to which the discursive context encouraged autobiographical reasoning. Other findings on storytelling suggest that older adults are quite good at adapting to different discourse contexts if those contexts are studied in vivo (Adams et al., 2002; Gould, 2004).

Another aspect of the discourse context worth consideration, however, is the fact that participants' purpose in these studies was to respond to an experimental request. In other work, the goal to seek meaning is particularly likely to result in phenomena like autobiographical reasoning (McLean \& Thorne, 2006; Pasupathi, in press; thus, situations in which experimenters request the production of a narrative may be likely to underestimate the extent of autobiographical reasoning in everyday life, particularly in contexts like those of the present study, in which the study procedures avoided pushing participants to seek meanings or insights. In a more traditional life story interview, the prompts interviewers use emphasize meaning and insights more directly.

In sum, the present findings, along with those of others (Bauer \& McAdams, 2005; Bluck \& Glueck, 2004), suggest that across adulthood, people become increasingly likely to construct personal narratives that contain autobiographical reasoning. The reasons behind the change and the implications for issues of adaptation remain open questions for future work. In this sense, narrative approaches to self-development have already served to open new frontiers for adult developmental research.

\section{References}

Adams, C. (1991). Qualitative age differences in memory for text: A life-span developmental perspective. Psychology and Aging, 6, 323-336.

Adams, C., Smith, M. C., Pasupathi, M., \& Vittolo, L. (2002). Social context effects on story recall in older and younger women: Does the listener make a difference? Journals of Gerontology, Series B: Psychological Sciences and Social Sciences, 57, P28-P40.

Alea, N., \& Bluck, S. (2006). I'll keep you in mind: The intimacy function of autobiographical memory in adulthood. Manuscript submitted for publication.

Bauer, J. J., \& Bonanno, G. A. (2001). Doing and being well (for the most part): Adaptive patterns of narrative self-evaluation during bereavement. Journal of Personality, 69, 451-482.

Bauer, J. J., \& McAdams, D. P. (2005). Interpreting the good life: Growth memories in the lives of mature, happy people. Journal of Personality and Social Psychology, 88, 203-216.

Blagov, P., \& Singer, J. A. (2004). Four dimensions of self-defining memories (specificity, meaning, content, and affect) and their relationships to self-restraint, distress, and repressive defensiveness. Journal of Personality, 72, 481-511.

Bluck, S., \& Glueck, J. (2004). Making things better and learning a lesson: Experiencing wisdom across the lifespan. Journal of Personality, 72, 543-572.

Bluck, S., \& Habermas, T. (2000). The life story schema. Motivation and Emotion, 24, 121-147.

Butler, R. N. (1963). The Life Review: An interpretation of reminiscence in the aged. Psychiatry, 26, 65-76.

Campbell, J. D., Trapnell, P. D., Heine, S. J., Katz, I. M., Lavallee, L. F., 
\& Lehman, D. R. (1996). Self-concept clarity: Measurement, personality correlates, and cultural boundaries. Journal of Personality and Social Psychology, 70, 141-156.

Carstensen, L. L. (1992). Social and emotional patterns in adulthood: Support for socioemotional selectivity theory. Psychology and Aging, 7, 331-338.

Carstensen, L. L. (1993). Motivation for social contact across the life span: A theory of socio-emotional selectivity. In J. Jacobs (Ed.), Nebraska Symposium on Motivation: Developmental perspectives on motivation (pp. 209-254). Lincoln: University of Nebraska Press.

Carstensen, L. L. (1995). Evidence for a life-span theory of socioemotional selectivity. Current Directions in Psychological Science, 4, 151-156.

Carstensen, L. L., Pasupathi, M., Mayr, U., \& Nesselroade, J. R. (2000). Emotions in everyday life across the adult life span. Journal of Personality and Social Psychology, 79, 644-655.

Conway, M. A., \& Holmes, A. (2004). Psychosocial stages and the accessibility of autobiographical memories across the life cycle. Journal of Personality, 72, 461-480.

Conway, M. A., \& Pleydell-Pearce, C. W. (2000). The construction of autobiographical memories in the self-memory system. Psychological Review, 107, 261-288.

Davis, C. G., Nolen-Hoeksema, S., \& Larson, J. (1998). Making sense of loss and benefiting from the experience: Two construals of meaning. Journal of Personality and Social Psychology, 75, 561-574.

Diehl, M., Hastings, C. T., \& Stanton, J. M. (2001). Self-concept differentiation across the adult life span. Psychology and Aging, 16, 643-654.

Donahue, E. M. (1994). Do children use the Big Five, too? Content and structural form in personality description. Journal of Personality, 62, $45-66$.

Erikson, E. H., \& Erikson, J. M. (1997). The life cycle completed: Extended version. New York: Norton.

Fivush, R., \& Schwarzmueller, A. (1989). Children remember childhood: Implications for childhood amnesia. Applied Cognitive Psychology, 12, 455-473.

Fung, H. H., Carstensen, L. L., \& Lutz, A. M. (1999). Influence of time on social preferences: Implications for life-span development. Psychology and Aging, 14, 595-604.

Fung, H. H., Lai, P., \& Ngu, R. (2001). Age differences in social preferences among Taiwanese and Mainland Chinese. Psychology and Aging, 16, 187-195

Gergen, K. J. (1991). The saturated self: Dilemmas of identity in contemporary life. New York: Basic Books.

Gould, O. (2004). Telling stories and getting acquainted: How age matters. In M. W. Pratt \& B. H. Fiese (Eds.), Family stories and the life course: Across time and generations (pp. 327-352). Mahwah, NJ: Erlbaum.

Gould, O. N., \& Dixon, R. A. (1993). How we spent our vacation: Collaborative storytelling by young and old adults. Psychology and Aging, 8, 10-17.

Gross, J. J., Carstensen, L. L., Pasupathi, M., Tsai, J., Skorpen, C., \& Hsu, A. Y. C. (1997). Emotion and aging: Experience, expression, and control. Psychology and Aging, 12, 590-599.

Habermas, T., \& Bluck, S. (2000). Getting a life: The development of the life story in adolescence. Psychological Bulletin, 126, 748-769.

Habermas, T., \& Paha, C. (2001). The development of coherence in adolescent's life narratives. Narrative Inquiry, 11(1), 35-54.

Harley, K., \& Reese, E. (1999). Origins of autobiographical memory. Developmental Psychology, 35, 1338-1348.

Harter, S. (1998). The development of self-representations. In N. Eisenberg \& W. Damon (Eds.), Handbook of child psychology (5th ed., Vol. 3, pp. 553-617). New York: Wiley.

Harter, S., \& Monsour, A. (1992). Developmental analysis of conflict caused by opposing attributes in the adolescent self-portrait. Developmental Psychology, 28, 251-260.

Higgins, E. T. (1996). The "self-digest": Self-knowledge serving self- regulatory functions. Journal of Personality and Social Psychology, 71, $1062-1083$.

Howe, M. L., \& Courage, M. L. (1993). On resolving the enigma of infantile amnesia. Psychological Bulletin, 113, 305-326.

James, L., Burke, D., Austin, A., \& Hulme, E. (1998). Production and perception of "verbosity" in younger and older adults. Psychology and Aging, 13, 355-367.

Kemper, S., Kynette, D., Rash, S., O’Brien, K., \& Sprott, R. (1989). Life-span changes to adults' language: Effects of memory and genre Applied Psycholinguistics, 10, 49-66.

Kemper, S., Rash, S., Kynette, D., \& Norman, S. (1990). Telling stories: The structure of adults' narratives. European Journal of Cognitive Psychology, 2, 205-228.

King, L. A., \& Patterson, C. (2000). Reconstructing life goals after the birth of a child with Down Syndrome: Finding happiness and growing. International Journal of Rehabilitation and Health, 5(1), 17-30.

King, L. A., \& Raspin, C. (2004). Lost and found possible selves, subjective well-being, and ego development in divorced women. Journal of Personality, 72, 603-632.

King, L. A., \& Smith, N. G. (2004). Gay and straight possible selves: Goals, identity, subjective well-being, and personality development. Journal of Personality, 72, 967-994.

Labouvie-Vief, G., Chiodo, L. M., Goguen, L. A., Diehl, M., \& Orwoll, L. (1995). Representations of self across the life span. Psychology and Aging, 10, 404-415.

Lang, F. L., \& Carstensen, L. L. (2002). Time counts: Future time perspective, goals, and social relationships. Psychology and Aging, 17, 125-139.

Lifton, R. J. (1999). The protean self: Human resilience in an age of fragmentation. Chicago: University of Chicago Press.

Locke, J. (1996). An essay concerning human understanding. In K. P. Winkler (Ed.), An esay concerning human understanding: Abridged and edited with an introduction and notes. Indianapolis, IN: Hackett. (Original work published 1690)

Markus, H., \& Nurius, P. (1987). Possible selves: The interface between motivation and the self-concept. In K. Yardley \& T. Honess (Eds.), Self and identity: Psychosocial perspectives (pp. 157-172). New York: Wiley.

Markus, H. R., \& Wurf, E. (1987). The dynamic self-concept: A social psychological perspective. Annual Review of Psychology, 38, 299-337.

Marsh, H. W., Parada, R. H., \& Ayotte, V. (2004). A multidimensional perspective of relations between self-concept (Self Description Questionnaire II) and adolescent mental health (Youth Self-Report). Psychological Assessment, 16, 27-41.

McAdams, D. P. (1993). The stories we live by: Personal myths and the making of the self. New York: Guilford Press.

McAdams, D. P. (1996). Personality, modernity, and the storied self: A contemporary framework for studying persons. Psychological Inquiry, 7, 295-321.

McAdams, D. P., Hoffman, B. J., Mansfield, E. D., \& Day, R. (1996). Themes of agency and communion in significant autobiographical scenes. Journal of Personality, 64, 339-377.

McLean, K. C., \& Pasupathi, M. (in press). Collaborative narration of the past and extraversion. Journal of Research in Personality.

McLean, K. C., \& Thorne, A. (2004). Late adolescents' self-defining memories about relationships. Developmental Psychology, 39, 635-645.

McLean, K. C., \& Thorne, A. (2006). Identity light: Entertainment stories as a vehicle for self-development. In D. McAdams, R. Josselson, \& A. Lieblich (Eds.), Identity and story: Creating self in narrative (pp. 111-127). Washington, DC: American Psychological Association.

Mergler, N. L., \& Goldstein, M. D. (1983). Why are there old people? Senescence as biological and cultural preparedness for the transmission of information. Human Development, 26, 72-90. 
Neisser, U. (1988). Five kinds of self-knowledge. Philosophical Psychology, 1, 35-59.

Nelson, K. (1991). Remembering and telling: A developmental story. Journal of Narrative and Life History, 1, 109-127.

Pals, J. L. (1999). Identity consolidation in early adulthood: Relations with ego-resiliency, the context of marriage, and personality change. Journal of Personality, 67, 295-329.

Pals, J. L. (2006a). Constructing the "springboard effect": Causal connections, self-making, and growth within the life story. In D. McAdams, R. Josselson, \& A. Lieblich (Eds.), Identity and story: Creating self in narrative (pp. 175-199). Washington, DC: American Psychological Association.

Pals, J. L. (2006b). The narrative identity processing of difficult life experiences: Pathways of personality development and positive selftransformation in adulthood. Journal of Personality, 74, 1080-1109.

Pasupathi, M. (2003). Social remembering for emotion regulation: Differences between emotions elicited during an event and emotions elicited when talking about it. Memory, 11, 151-163.

Pasupathi, M. (in press). Telling and the remembered self: Linguistic differences in memories for previously disclosed and previously undisclosed events. Memory.

Pasupathi, M., \& Carstensen, L. L. (2003). Age and emotion during mutual reminiscing. Psychology and Aging, 18, 430-442.

Pasupathi, M., \& Mansour, E. (2003). [A study of narratives about recent self-relevant experiences in a sample of college students]. Unpublished raw data.

Pasupathi, M., Mansour, E., \& Brubaker, J. (2006). Stability, change, and continuity of self in personal storytelling: Using autobiographical narratives to study self development. Manuscript submitted for publication.

Pasupathi, M., \& Rich, B. (2005). Inattentive listening undermines selfverification in personal storytelling. Journal of Personality, 73, 10511085.

Pennebaker, J. W., \& Keough, K. (1999). Revealing, organizing, and reorganizing the self in response to stress and emotion. In R. J. Contrada
\& R. D. Ashmore (Eds.), Self, social identity, and physical health: Interdisciplinary explorations (Vol. 2, pp. 101-121). London: Oxford University Press.

Pratt, M. W., \& Robins, S. L. (1991). That's the way it was: Age differences in the structure and quality of adults' personal narratives. Discourse Processes, 14, 73-85.

Reese, E., \& Brown, N. (2000). Reminiscing and recounting in the preschool years. Applied Cognitive Psychology, 14, 1-17.

Rochat, P. (2001). Origins of self-concept. In G. Bremner \& A. Fogel (Eds.), Blackwell handbook of infant development (pp. 191-212). Malden, MA: Blackwell.

Singer, J. A., \& Salovey, P. (1993). The remembered self: Emotion and memory in personality. New York: Free Press.

Smyth, J. M. (1998). Written emotional expression: Effect sizes, outcome types, and moderating variables. Journal of Consulting and Clinical Psychology, 66, 174-184.

Thorne, A. (1995). Developmental truths in memories of childhood and adolescence. Journal of Personality, 63, 139-163.

Thorne, A. (2000). Personal memory telling and personality development. Personality and Social Psychology Review, 4(1), 45-56.

Thorne, A., \& McLean, K. C. (2003). Telling traumatic events in adolescence: A study of master narrative positioning. In R. Fivush \& C. Haden (Eds.), Autobiographical memory and the construction of a narrative self: Developmental and cultural perspectives (pp. 169-185). Mahwah, NJ: Erlbaum.

Thorne, A., McLean, K. C., \& Lawrence, A. M. (2004). When remembering is not enough: Reflecting on self-defining memories in late adolescence. Journal of Personality, 72, 513-541.

Wong, P. T. P., \& Watt, L. M. (1991). What types of reminiscence are associated with successful aging? Psychology and Aging, 6, 272-279.

Received September 28, 2004

Revision received November 1, 2005

Accepted November 14, 2005 